\title{
SURGICAL TREATMENT FOR BOTH PULMONARY AND HEPATIC METASTASES FROM COLORECTAL CANCER
}

Koichi Kobayashi, MD

Masafumi Kawamura, MD

Tsuneo Ishihara, MD
Objective: The role of surgery in the treatment of patients with pulmonary and hepatic metastases from colorectal cancer has not been delineated. Methods: Of the 351 patients enrolled in the Metastatic Lung Tumor Study Group of Japan between June 1988 and June 1996 who underwent thoracotomy for pulmonary metastases from colorectal cancer, 47 also underwent hepatic resection for metastatic tumors. The records of these patients were studied. Results: The 47 patients who underwent pulmonary and hepatic resection had a 3-year survival of $36 \% \pm 8 \%$, a 5-year survival of $31 \% \pm 8 \%$, and an 8-year survival of $23 \% \pm 9 \%$. The longest survival was 98 months. This patient was alive without recurrence. There was a significant difference in the cumulative survival of the patients with a solitary pulmonary metastasis and the patients with multiple pulmonary metastases $(P=.04)$. Neither age, sex, location of the primary tumor, maximum diameter of the pulmonary metastases, method of pulmonary resection, number of hepatic metastases, nor method of hepatic resection was correlated with survival. However, 9 of 10 patients who survived 3 years or more after the initial thoracotomy had only one or two hepatic metastases. Conclusion: Surgical treatment of a solitary pulmonary metastasis concurrent with or after resection of hepatic metastases from colorectal cancer may be appropriate if the hepatic metastases are resectable for cure. Patients with a solitary pulmonary metastasis and a small number of hepatic metastases are good candidates for resection. Long-term survival can be expected. (J Thorac Cardiovasc Surg 1999;118:1090-6)
S urgical treatment for pulmonary metastases from colorectal cancer has been discussed since Thomford, Woolner, and Clagett ${ }^{1}$ first reported the criteria for the resection of metastatic lung tumors in 1965. The utility of surgery in the treatment of patients with pulmonary metastases from colorectal cancer is generally accepted, despite the fact that no prospective study demonstrated its efficacy. In practice, many patients survive more than 5 years after resection of their pulmonary metastases. The effectiveness of the resection of pulmonary metastases from colorectal cancer in

From the Metastatic Lung Tumor Study Group of Japan, Tokyo, Japan. Received for publication Jan 25, 1999; revisions requested May 4, 1999; revisions received July 19, 1999; accepted for publication Aug 11, 1999.

Address for reprints: Koichi Kobayashi, MD, Department of Surgery, School of Medicine, Keio University, 35 Shinanomachi, Shinjuku-ku, Tokyo, 160-8582 Japan (E-mail: kawamura@med.keio.ac.jp).

Copyright $\odot 1999$ by Mosby, Inc.

$0022-5223 / 99 \$ 8.00+0 \quad \mathbf{1 2} / \mathbf{1} / \mathbf{1 0 2 4 8 1}$ patients with hepatic metastases has not been discussed extensively because of a general understanding that involvement of other organs is a contraindication to surgery. ${ }^{1}$

Of the 351 patients in the Metastatic Lung Tumor Study Group of Japan (MLTSGJ) who underwent pulmonary resection for metastatic tumor from colorectal cancer, 47 patients underwent hepatectomy for metastatic tumors. We reviewed the characteristics of these 47 patients in an attempt to elucidate the effectiveness of surgical treatment in this population.

\section{Patients and methods}

A total of 351 patients from 11 hospitals in the Greater Tokyo Metropolitan Area who underwent thoracotomy for pulmonary metastases resulting from colorectal cancer were registered in the MLTSGJ between June 1988 and June 1996. Of these patients, 47 underwent curative pulmonary and hepatic resection for metastatic tumors. These patients' characteristics are shown in Table I. Twenty-one patients had a solitary pulmonary metastasis. The average number of metastatic pulmonary tumors was 2.5 . Of the 26 patients with 
Table I. Characteristics of 47 patients undergoing resections of both hepatic and pulmonary metastases

\begin{tabular}{|c|c|}
\hline & No. of patients \\
\hline \multicolumn{2}{|l|}{ Sex } \\
\hline Male & 30 \\
\hline Female & 17 \\
\hline \multicolumn{2}{|l|}{ Age } \\
\hline$\geq 60 \mathrm{y}$ & 27 \\
\hline$<60 \mathrm{y}$ & 19 \\
\hline Unknown & 1 \\
\hline Average & 59 \\
\hline Range & $40-82$ \\
\hline \multicolumn{2}{|c|}{ No. of pulmonary metastases } \\
\hline Solitary & 21 \\
\hline $2-3$ & 17 \\
\hline $4-5$ & 5 \\
\hline$\geq 6$ & 4 \\
\hline \multicolumn{2}{|c|}{ Maximum size of pulmonary metastases } \\
\hline$<2.0 \mathrm{~cm}$ & 19 \\
\hline $2.0-2.9 \mathrm{~cm}$ & 11 \\
\hline $3.0-4.9 \mathrm{~cm}$ & 12 \\
\hline$\geq 5.0$ & 3 \\
\hline Unknown & 2 \\
\hline \multicolumn{2}{|c|}{ No. of hepatic metastases } \\
\hline Solitary & 30 \\
\hline 2 & 11 \\
\hline 3 & 2 \\
\hline 4 & 4 \\
\hline \multicolumn{2}{|c|}{ Mode of pulmonary resection } \\
\hline Wedge resection & 18 \\
\hline Segmentectomy & 14 \\
\hline Lobectomy & 15 \\
\hline \multicolumn{2}{|c|}{ Location of primary cancer } \\
\hline Colon & 26 \\
\hline Ascending & 4 \\
\hline Sigmoid & 22 \\
\hline Rectum & 17 \\
\hline Unknown & 4 \\
\hline \multicolumn{2}{|c|}{ Interval between primary and pulmonary metastases } \\
\hline Synchronous & 8 \\
\hline$<1 \mathrm{y}$ & 6 \\
\hline $1 \leq,<2 \mathrm{y}$ & 13 \\
\hline $2 \leq,<3 \mathrm{y}$ & 4 \\
\hline $3 \leq,<4 \mathrm{y}$ & 10 \\
\hline $4 y \leq$ & 6 \\
\hline \multicolumn{2}{|c|}{ Combination therapy for hepatic metastases } \\
\hline Done & 27 \\
\hline No & 13 \\
\hline Unknown & 7 \\
\hline
\end{tabular}

multiple pulmonary metastases, 9 had bilateral metastases. Bilateral thoracotomies were performed simultaneously in 7 of these patients. Thirty patients had a solitary hepatic metastasis. The average number of hepatic metastases was 1.6. Pulmonary surgery included wedge resection $(n=18)$, segmentectomy $(\mathrm{n}=14)$, and lobectomy $(\mathrm{n}=15)$. Hepatic surgery included partial resection or enucleation $(\mathrm{n}=15)$, subsegmentectomy or segmentectomy $(n=12)$, bisegmentec-

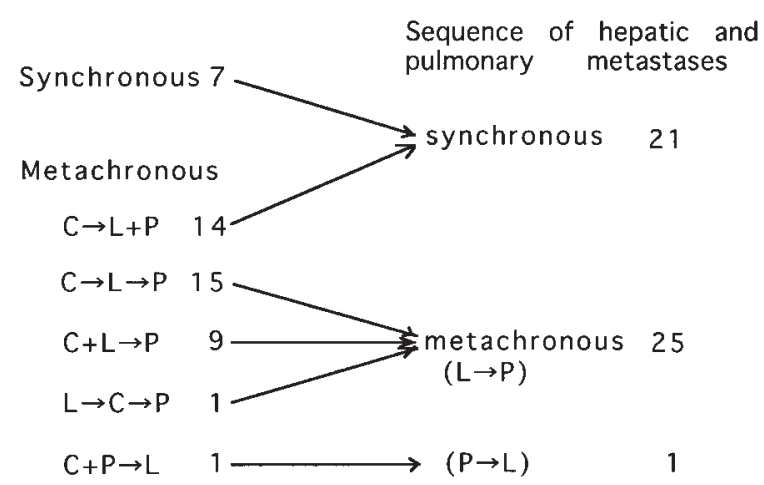

Fig 1. Timing and sequence of pulmonary metastases, hepatic metastases, and primary colorectal cancer. $C$, Colorectal cancer; $L$, hepatic metastases; $P$, pulmonary metastases.

tomy $(\mathrm{n}=2)$, and lobectomy $(\mathrm{n}=16)$. The type of hepatic operation was unknown in 2 patients.

Timing and sequence of pulmonary and hepatic metastases in relation to colorectal cancer resection are shown in Fig 1. In 25 patients, hepatic metastases were resected before the pulmonary metastases were detected. The mean interval between the 2 resections was 23.8 months. No patient in this subset had a recurrent hepatic tumor or evidence of residual hepatic tumor when the pulmonary metastases were discovered. Of the 21 patients with both pulmonary and hepatic metastases detected simultaneously, 13 underwent hepatectomy before thoracotomy. The interval between operations ranged from 1 to 7 months (mean 2.6 months). Six of the 21 patients underwent hepatectomy and thoracotomy at the same time. In 2 patients, thoracotomy was followed by hepatectomy. In 1 patient the pulmonary metastases were detected 9 months before the hepatic metastasis.

Vital status was available in the respective databases. For 21 patients alive when their medical records were retrieved, the interviews were performed at the outpatient offices of the respective hospitals to update vital status. Five patients were lost to follow-up at this time. Follow-up periods of these patients after last resections were 4, 11, 23, 28, and 35 months.

In the analysis of survival, 2 types of time 0 were used. One type of the time 0 was set to be the time at which last resection of metastases was undertaken. This is the time at which all the patients had both hepatic and pulmonary metastases resected. Another type of the time 0 was set to be the time at which initial resection of metastases was undertaken. This is the time at which 3 patients underwent pulmonary resection and the other patients underwent hepatectomy or both hepatectomy and pulmonary resection for their initial metastasectomy.

As this study was multi-institutional, pathologic diagnoses were made by the pathologists belonging to the respective institutions. When the specimens of pulmonary metastatic lesions required pathologic analysis to eliminate second primary tumors, they were necessarily compared with the spec- 


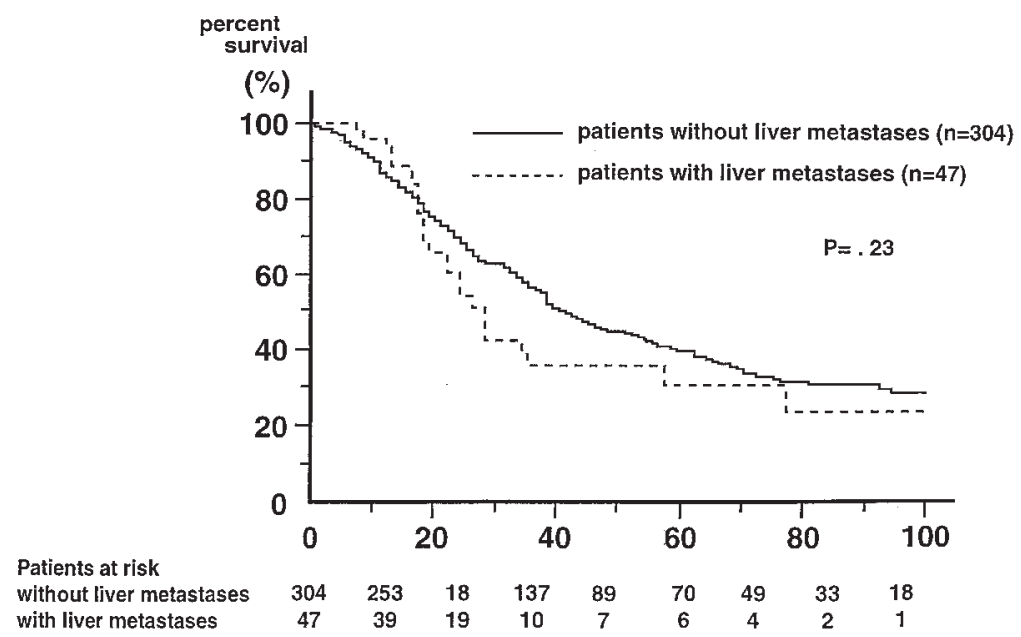

Fig 2. Kaplan-Meier survival analysis: Months after the last resection of metastases of the patients with liver metastases and the patients without liver metastases. The $P$ value of overall log-rank test is .23 .

imens of primary colorectal tumors. When they had the same pathologic features as those of the primary lesions, they were diagnosed as pulmonary metastases.

Statistical analysis. The survival from the initial or the last metastasectomy was calculated by means of the KaplanMeier method. ${ }^{2}$ The significance of each prognostic factor was determined by means of the log-rank test.

For the identification of prognostic factors, multivariable analyses were done by the Cox semiparametric proportional hazards regression. The following variables were entered into the multivariable analyses: age, sex, site of colorectal primary tumor (colon or rectum), date of colorectal resection, sequence of metastases, number of hepatic metastases, number of pulmonary metastases, date of pulmonary resection, date of hepatic resection, follow-up date, and vital status. A $P$ value $<.05$ was considered prognostic.

\section{Results}

The cumulative survival from the last metastasectomy was calculated for the 47 patients who underwent resection of pulmonary and hepatic metastases and the 304 patients who underwent resection of only pulmonary metastases (Fig 2). The patients who underwent pulmonary and hepatic resection had a 3 -year survival of $36 \% \pm 8 \%$, a 5 -year survival of $31 \% \pm 8 \%$, and an 8 -year survival of $23 \% \pm 9 \%$. The longest survival was 98 months. This patient was alive without recurrence. The patients who underwent pulmonary resection alone had a 3-year survival of $56 \% \pm 3 \%$, a 5 -year survival of $40 \% \pm 3 \%$, and an 8-year survival of $28 \% \pm$ $3 \%$. No significant difference was noted in survival between these 2 groups at confidence intervals of $95 \%$ $(P=.23)$.

The cumulative survivals after the last metastasecto- my and after the initial metastasectomy were calculated for the 21 patients in whom the hepatic and pulmonary metastases were detected simultaneously and the 25 patients in whom the hepatic metastases were detected before the pulmonary metastases (Figs 3 and 4). There was no significant difference in survival after the last metastasectomy between these 2 groups $(P=$ .97). On the other hand, the cumulative survival at 5 years after the initial metastasectomy was $22 \% \pm 12 \%$ in the patients with the hepatic and pulmonary metastases simultaneously and $50 \% \pm 11 \%$ in the patients in whom the hepatic metastases were detected before the pulmonary metastases. There was a significant difference in survival after the initial metastasectomy between these 2 groups $(P=.009)$.

The cumulative survival from the last metastasectomy was calculated for the 21 patients with a solitary pulmonary metastasis and the 26 patients with multiple pulmonary metastases (Fig 5). The patients with a solitary pulmonary metastasis had a 3-year survival of $48 \%$ $\pm 12 \%$, a 5 -year survival of $40 \% \pm 12 \%$, and an 8 -year survival of $40 \% \pm 12 \%$. The patients with multiple pulmonary metastases had a 3-year survival of $30 \% \pm$ $12 \%$, a 5 -year survival of $22 \% \pm 11 \%$, and an 8 -year survival of $0 \%$. A significant difference in cumulative survival was seen between these 2 groups $(P=.04)$.

In the 21 patients with a solitary pulmonary metastasis, a wedge resection $(n=7)$, segmentectomy $(n=7)$, or lobectomy $(\mathrm{n}=7)$ was performed. In the 26 patients with multiple pulmonary metastases, a wedge resection $(n=11)$, segmentectomy $(n=7)$, or lobectomy $(n=8)$ was performed. The 5-year survival of the 32 patients who underwent wedge resection or segmentectomy 


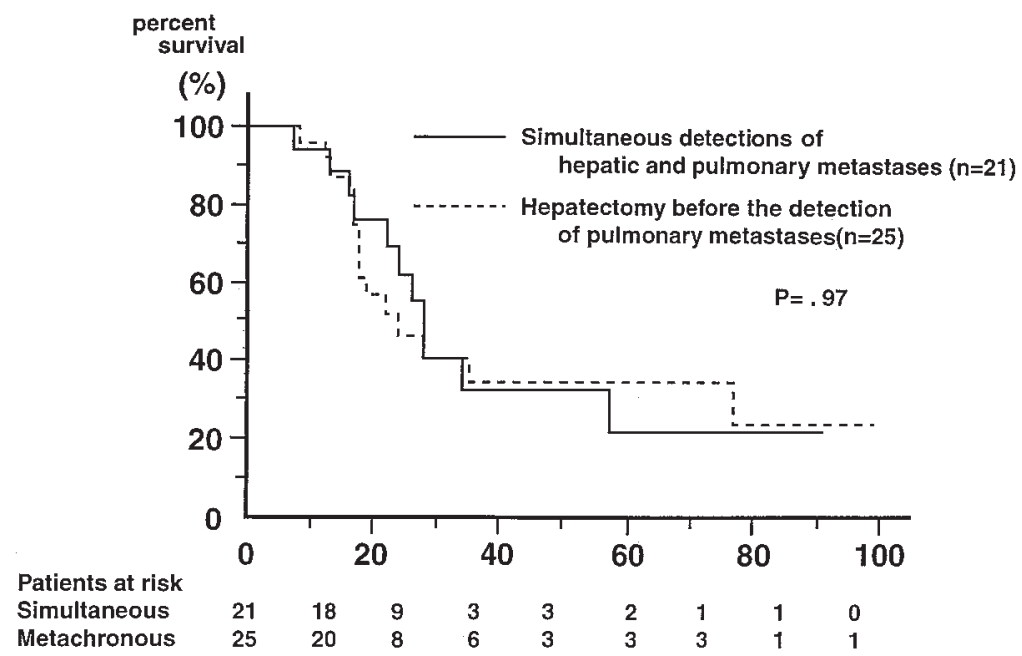

Fig 3. Kaplan-Meier survival analysis: Months after the last resection of metastases of the patients with simultaneously detected hepatic and pulmonary metastases and the patients who underwent hepatectomy before the detection of pulmonary metastases. The $P$ value of the overall log-rank test is .97 .

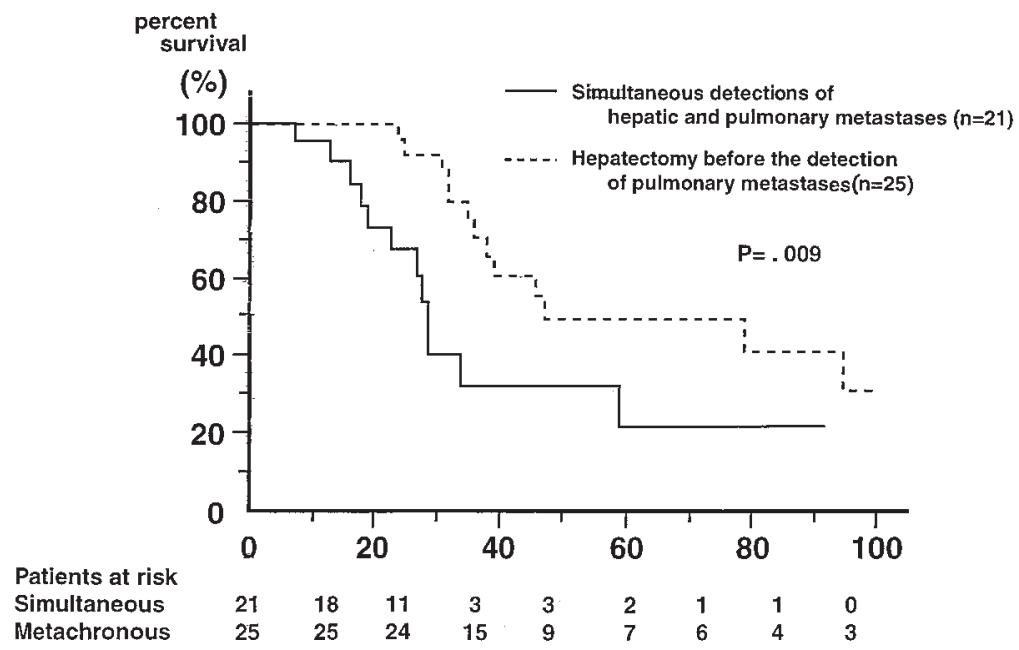

Fig 4. Kaplan-Meier survival analysis: Months after the initial resection of metastases of the patients with simultaneously detected hepatic and pulmonary metastases and the patients who underwent hepatectomy before the detection of pulmonary metastases. The $P$ value of the overall log-rank test is .009 .

was worse than that of the 15 patients who underwent lobectomy ( $22 \%$ vs $44 \%$, respectively). However, there was no significant difference in the survivals between these 2 groups $(P=.40)$. Although the number of hepatic metastases did not affect the cumulative survival after thoracotomy, there were no 8-year survivors among the patients with multiple hepatic metastases.

Multivariable analysis shows that the only prognostic factor after the last metastasectomy was the number of pulmonary metastases $(P=.045$, Table II). On the other hand, prognostic factors after the initial metastasecto- my were revealed to be the number of pulmonary metastases $(P=.011)$ and the timing of the detection of hepatic and pulmonary metastases $(P=.002$, Table III).

Of the 47 patients who underwent pulmonary and hepatic resection, 10 survived more than 3 years after the last metastasectomy. There were 2 deaths due to recurrences in this group, 1 at 57 months and 1 at 76 months. The remaining 8 patients were alive at the time of this study, 41 to 99 months after resection. Two of these patients had recurrent tumors. In 7 of these 


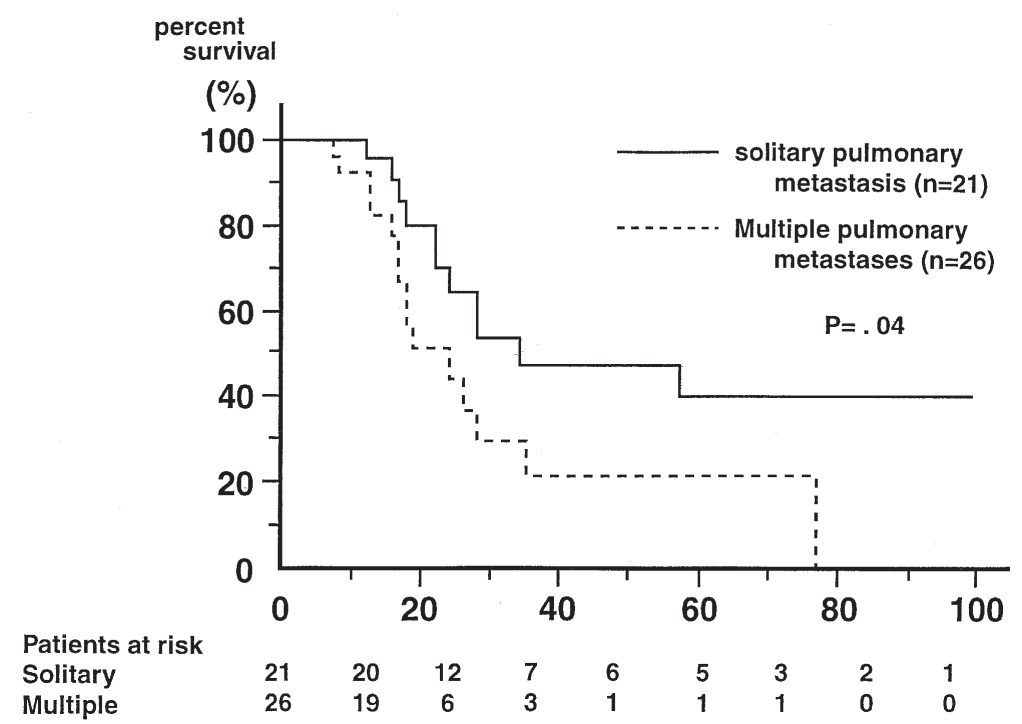

Fig 5. Kaplan-Meier survival analysis: Months after the last resection of metastases of the patients with solitary pulmonary metastasis and the patients with multiple pulmonary metastases. The $P$ value of the overall log-rank test is .04 .

Table II. Relationship of individual variables to death after the last metastasectomy (Cox proportional hazards method)

\begin{tabular}{|c|c|c|c|}
\hline Variable/responses & $\mathrm{P}$ value & Hazard ratio & $95 \% C L$ \\
\hline Sex & 6 & 1.276 & $.511-3.186$ \\
\hline Age $(60 \leq, 60>y)$ & .3 & .619 & $.263-1.458$ \\
\hline $\begin{array}{l}\text { Location of primary cancer } \\
\text { (colon/rectum) }\end{array}$ & .4 & .682 & $.268-1.738$ \\
\hline $\begin{array}{l}\text { Timing of hepatectomy and } \\
\text { pulmonary resection } \\
\text { (synchronous/metachronous) }\end{array}$ & .7 & .868 & $.376-2.001$ \\
\hline $\begin{array}{l}\text { No. of pulmonary metastases } \\
\text { (solitary/multiple) }\end{array}$ & .04 & 2.410 & $1.020-5.696$ \\
\hline $\begin{array}{l}\text { No. of liver metastases } \\
\text { (solitary/multiple) }\end{array}$ & .9 & .965 & $.398-2.337$ \\
\hline
\end{tabular}

$C L$, Confidence limit.

patients, the pulmonary metastasis was solitary. In 6, the hepatic metastasis was solitary. In 5, both metastases were solitary. In 1 patient, the primary colorectal lesion and the pulmonary metastases were detected at the same time. In the other 9 patients, the pulmonary metastases were detected 15 to 44 months after the treatment of the primary colorectal tumor. The intervals were greater than 2 years in 6 patients.

\section{Discussion}

Goldberg and associates ${ }^{3}$ have reported that among 548 patients with recurrent colorectal cancer, $222(41 \%)$ underwent resection, $28(5.1 \%)$ underwent hepatecto-
Table III. Relationship of individual variables to death after the resection of hepatic metastases (Cox proportional hazards method)

\begin{tabular}{|c|c|c|c|}
\hline Variable/responses & $\mathrm{P}$ value & Hazard ratio & $95 \% C L$ \\
\hline Sex & .8 & 1.103 & $.446-2.726$ \\
\hline Age $(60 \leq, 60>y)$ & 6 & .803 & $.331-1.947$ \\
\hline $\begin{array}{l}\text { Location of primary cancer } \\
\text { (colon/rectum) }\end{array}$ & .4 & .677 & $.253-1.807$ \\
\hline $\begin{array}{l}\text { Timing of hepatectomy and } \\
\text { pulmonary resection } \\
\text { (synchronous/metachronous) }\end{array}$ & .002 & .205 & $.075-.563$ \\
\hline $\begin{array}{l}\text { No. of pulmonary metastases } \\
\text { (solitary/multiple) }\end{array}$ & .01 & 3.640 & $1.353-9.794$ \\
\hline $\begin{array}{l}\text { No. of liver metastases } \\
\text { (solitary/multiple) }\end{array}$ & .8 & .882 & $.362-2.146$ \\
\hline
\end{tabular}

$C L$, Confidence limit.

my, and 20 (3.0\%) underwent thoracotomy. Yamamoto and colleagues ${ }^{4}$ have reported that of 974 patients who underwent resection of a primary colorectal cancer, 47 (4.8\%) had a hepatic metastasis develop. Among them, $16(2.9 \%)$ underwent reoperation, but only $6(0.6 \%)$ of the reoperations were curative. Of the $35(3.6 \%)$ patients who had pulmonary metastases, only $6(0.6 \%)$ underwent a curative reoperation. The patients enrolled in this study comprised $13 \%$ of the 351 cases in the MLTSGJ in which pulmonary metastases from colorectal cancer were resected. Thus these cases are not rare. It is therefore important to determine the criteria for resection of both pulmonary and hepatic metastases. 
In approximately half of the cases, the pulmonary and hepatic metastases were detected at the same time. In the other half, detection of the hepatic metastases preceded detection of the pulmonary metastases. In only 1 case, detection of the pulmonary metastasis preceded that of the hepatic metastases. Although this may be due partly to the fact that the patients in this study were registered mainly by thoracic surgeons, we can assume that resectable hepatic metastases appear before or at the time of detection of pulmonary metastases in most cases. Therefore the cases in which the detection of the hepatic metastases preceded or concurred with the detection of the pulmonary metastases are discussed.

The 5-year survivals after thoracotomy for pulmonary metastases from colorectal cancer have been reported to range from $22 \%$ to $42 \% .^{5-8}$ Our data for the 47 patients with both pulmonary and hepatic metastases were also within this range. This means that surgical treatment in patients with both pulmonary and hepatic metastases may be appropriate. Extrahepatic disease has been reported to be a poor prognostic factor for the resection of hepatic metastases from colorectal cancer. In this study, the 5-year survival after metastasectomy in the synchronous group was $22 \%$. This is in contrast to the 5 -year survival of $0 \%$ to $13 \%$ reported for other extrahepatic disease. ${ }^{9-11}$ Moreover, the 5-year survivals after hepatic resection of colorectal metastases have been reported to range from $24 \%$ to $41 \%$. $^{9-15}$ These data suggest that synchronous pulmonary metastases with hepatic metastases may be different from other extrahepatic diseases and should not be thought of as a poor prognostic factor for hepatectomy.

On the other hand, the 5-year survival of the synchronous group after initial metastasectomy was also significantly poorer than that of the metachronous group. However, in the cumulative survival from the last metastasectomy, there was no significant difference between these 2 groups, because pulmonary metastases developed 23.8 months after hepatectomy in the metachronous group. Multivariable analysis also shows that the prognostic factor after the last metastasectomy was only the number of pulmonary metastases, although the number of pulmonary metastases and timing of the detection of hepatic and pulmonary metastases were prognostic factors after the initial metastasectomy. This means that the prognosis after the last metastasectomy, that is, after pulmonary resection of colorectal metastases, is independent of the timing of metastases. Robinson and coworkers ${ }^{16}$ reported a similar conclusion that if the date of last resection is chosen for the calculation of survival, the timing of metastases is no longer a factor that influences survival.

Only the number of pulmonary metastases affected the survival after the last metastasectomy in patients with both pulmonary and hepatic metastases. Okumura and associates ${ }^{5}$ reported that the 5-year survival after thoracotomy in 22 patients with hepatic metastases and a solitary pulmonary metastasis was $43.7 \%$. In our study, the 5-year survival among patients with a solitary pulmonary metastasis was $40 \%$. Such individuals are good candidates for surgical treatment. The number of liver metastases was not correlated with survival after thoracotomy. However, most of the patients who survived more than 3 years had 1 or 2 hepatic metastases. Therefore surgery may be most effective in patients with few hepatic metastases. More data are needed to establish this pattern as valid.

Among the 21 patients with concurrent pulmonary and hepatic metastases, 6 underwent simultaneous pulmonary and hepatic resection. The operative procedures included lobectomies for pulmonary and hepatic metastases in 1 patient and lobectomy and partial resection for bilateral pulmonary metastases and segmentectomy for a hepatic metastasis in 1 patient. Segmentectomy for pulmonary metastases and partial resection for hepatic metastases was performed in 4 patients. In another 8 patients, the interval between the 2 resections was less than 2 months. When thinking of resection for concurrent pulmonary and hepatic metastases, one must consider the invasiveness of the surgical procedure. After concurrent resection or resection within 2 months, no operative death or deaths within 6 months occurred. This indicates that it is safe to perform these procedures concurrently or at close intervals.

In conclusion, resection of pulmonary metastases concurrent with or after resection of hepatic metastases from colorectal cancer may be appropriate. Patients with a solitary pulmonary metastasis and few hepatic metastases are good candidates for this operation. Long-term survival can be expected in these patients.

\section{REFERENCES}

1. Thomford NR, Woolner LB, Clagett OT. The surgical treatment of metastatic tumors in the lung. J Thorac Cardiovasc Surg 1965; 49:357-63.

2. Kaplan EL, Meier P. Nonparametric estimation from incomplete observations. J Am Stat Assoc 1958;53:457-81.

3. Goldberg RM, Fleming TR, Tangen CM, Moertel CG, MacDonald JS, Haller DG, et al. Surgery for recurrent colon cancer: strategies for identifying resectable recurrence and success rates after resection. Ann Intern Med 1998;129:27-35.

4. Yamamoto Y, Imai H, Iwamoto S, Kasai Y, Tsunoda T. Surgical treatment for the recurrence of colorectal cancer. Surg Today 1996;26:164-8. 
5. Okumura S, Kondo H, Tsuboi M, Nakayama H, Asamura H, Tsutiya $\mathrm{R}$, et al. Pulmonary resection for metastatic colorectal cancer: experience with 159 patients. J Thorac Cardiovasc Surg 1996;112:867-74.

6. Brister SJ, De Varennes B, Gordon PH, Sheiner NM, Pym J. Contemporary operative management of pulmonary metastases of colorectal origin. Dis Colon Rectum 1988;31:786-92.

7. McAfee MK, Allen MS, Trastek VF, Ilstrup DM, Deschamps C, Pairolero PC. Colorectal lung metastases: results of surgical excision. Ann Thorac Surg 1992;53:780-6.

8. Yano T, Hara N, Ichinose Y, Yokoyama H, Miura T, Ohta M. Results of pulmonary resection of metastatic colorectal cancer and its application. J Thorac Cardiovasc Surg 1993;106:875-9.

9. Stangl R, Hofmann AA, Charnley RM, Scheele J. Factors influencing the natural history of colorectal liver metastases. Lancet 1994;343:1405-10.

10. Gayowski TJ, Iwatsuki S, Madariago JR, Selby R, Todo S, Irish $\mathrm{W}$, et al. Experience in hepatic resection for metastatic colorectal cancer: analysis of clinical and pathological risk factors. Surgery 1994;116:703-11.

11. Jenkins LT, Millikan KW, Bines SD, Staren ED, Doolas A. Hepatic resection for metastatic colorectal cancer. Am Surg 1997; 63:605-10.

12. Nakamura S, Suzuki S, Baba S. Resection of liver metastases of colorectal carcinoma. World J Surg 1997;21:741-7.
13. Jamison RL, Donohue JH, Nagorney DM, Rosen CB, Harmsen WS, Ilstrup DM. Hepatic resection for metastatic colorectal cancer results in cure for some patients. Arch Surg 1997;132:50510.

14. Fong Y, Kemeny N, Paty P, Blumgart LH, Cohen AM. Treatment of colorectal cancer: hepatic metastasis. Semin Surg Oncol 1996; 12:219-52.

15. Wanebo HJ, Chu QD, Vezeridis P, Soderberg C. Patient selection for hepatic resection of colorectal metastases. Arch Surg 1996; 131:322-9.

16. Robinson BJ, Rice TW, Strong SA, Rybicki LA, Blackstone EH. Is resection of pulmonary and hepatic metastases warranted in patients with colorectal cancer? J Thorac Cardiovasc Surg 1999; 117:66-76.

\section{Appendix}

The following institutions participated in this study: Keio University, Cancer Institute Hospital, Chiba University, Dokkyo University, Hamamatsu University, National Cancer Center, National Defense Medical College, Saitama Medical School, Tokyo Medical University, Tokyo Metropolitan University, and University of Tokyo.

\section{Availability of Journal back issues}

As a service to our subscribers, copies of back issues of The Journal of Thoracic and Cardiovascular Surgery for the preceding 5 years are maintained and are available for purchase from Mosby at a cost of $\$ 17.00$ per issue until inventory is depleted. The following quantity discounts are available: $25 \%$ off on quantities of 12 to 23 , and one third off on quantities of 24 or more. Please write to Mosby, Inc, Subscription Services, 11830 Westline Industrial Drive, St Louis, MO 63146-3318, or call 800-453-4351 or 314-453-4351 for information on availability of particular issues. If unavailable from the publisher, photocopies of complete issues may be purchased from Bell \& Howell Information and Learning, 300 N Zeeb Rd, Ann Arbor, MI 48106-1346; 734-761-4700 or 800-521-0600. 